\title{
Downsizing Survivors' Communication Networks and Reactions: \\ A Longitudinal Examination of Information Flow and Turnover Intentions
}

\author{
Alex M. Susskind \\ Cornell University
}

Final version published April 2007 in Communication Research vol. 34, iss. 2, pg 156-184

\begin{abstract}
Author Note
Alex M. Susskind is an associate professor at the School of Hotel Administration and an appointed member to the Graduate Fields of Hotel Administration and Communication at Cornell University. He earned his $\mathrm{PhD}$ in communication from Michigan State University with cognates in organizational communication and organizational behavior where he also earned his MBA with a concentration in personnel and human relations. His research is based primarily in organizational communication and organizational behavior. He is currently researching: (a) the influence of customer-service provider interaction as it relates to organizational effectiveness and efficiency from the perspective of guests, employees, and managers and (b) the influence of communication relationships on individuals'work-related attitudes and perceptions surrounding organizational events and processes such as teamwork and downsizing.
\end{abstract}


An earlier version of this manuscript was presented at the 51st annual conference of the International Communication Association, Washington, D.C., May 2001. I would like to thank Vernon D. Miller, J. David Johnson, Franklin J. Boster, Georgia T. Chao, and Ronald F. Cichy for their help in shaping this project. I would also like to thank Daniel R. Ilgen and John A. Wagner III for their useful comments and suggestions on several earlier versions of this manuscript. More recently, J. David Johnson, Herminia Ibarra, and two anonymous provided extensive comments that have substantially improved this manuscript. 


\begin{abstract}
The pre- and postdownsizing information flow and postdownsizing turnover intentions of downsizing survivors were examined in the corporate office of an international hotel company. Using a combination of network analysis and path analysis, the relationship between changes in downsizing survivors' betweenness centrality and perceptions of information adequacy relative to reported turnover intentions were examined across two postdownsizing time periods. Results of the path analyses provided general support for the model as hypothesized, indicating in postdownsizing periods that changes to network members' network centrality positively influenced changes in their perceptions of information adequacy, which then negatively influenced their turnover intentions. The article concludes with a discussion of the support for the hypotheses and the study's limitations and pragmatic implications.
\end{abstract}

Keywords: communication networks; downsizing; longitudinal network analysis 


\section{Downsizing Survivors' Communication Networks and Reactions: A Longitudinal Examination of Information Flow and Turnover Intentions}

Organizational downsizing is a disruptive process that affects the communication patterns, perceptions, and attitudes of surviving employees (Brockner, 1988; Brockner et al., 1997; Shah, 2000). Downsizing survivors are likely to face many changes in their work environment, including the loss of ties to information sources and the loss of direct and indirect links to individuals with power and influence in the network. A number of investigations examined the effects of organizational downsizing on surviving employees (see reviews by Brockner, 1988, and Kozlowski, Chao, Smith, \& Hedlund, 1993). Although the existing studies of downsizing provide valuable insights into the effects of downsizing on individuals' attitudes, little research examines downsizing's longitudinal influence on survivors (Kozlowski et al., 1993; Mishra \& Spreitzer, 1998). A lack of attention to downsizing's longterm effect is particularly surprising given that (a) network reconfigurations are likely to have considerable impact on organizational power and influence structures, work processes, and employee attitudes (Brass \& Burkhardt, 1993) and (b) it is unclear how organizational members cope with lost communication linkages and the need to form new linkages.

In this article, I suggest that downsizing survivors' perceptions of information adequacy are uniquely influenced by changes in network centrality, and changes to perceptions of information adequacy influence downsizing survivors' desire to remain employed with the company. First, I proceed by discussing organizational change and downsizing. Next, I discuss how downsizing is likely to influence communication networks and in particular network centrality, and finally, I present a discussion of network centrality and its proposed relationship 
to downsizing survivors' perceptions of information adequacy and how turnover intentions are influenced by changes in information flow across a downsizing event.

\section{Organizational Change and Downsizing}

For survivors, downsizing often leads to feelings of uncertainty, guilt, or anger (Gutknecht \& Keys, 1993; O’Neill \& Lenn, 1995). Brockner, Weisenfeld, Reed, Grover, and Martin (1993) reported that employees' attitudes toward a downsizing effort depend on (a) how fairly the survivors feel the layoffs were handled and (b) their perceptions of their coworkers' reactions to the layoffs. If survivors sense that the downsizing was handled in an unfair manner, they are likely to define their new work context as unfair, harbor feelings of distrust and uncertainty toward the organization (Brockner et al., 1993), and be less accepting of the resulting changes (Susskind, Miller, \& Johnson, 1998). In a series of studies, Brockner et al. (1997) also found that survivors take cues from other organizational members as to how to respond to their new environment and indicated that those individuals who are prominent in the organization before the downsizing are more likely to be influential following the downsizing. Although downsizing is often associated with negative reactions, a reduced workforce can also bring a new sense of efficiency, effectiveness, or relief to an organization and its members (Brockner, 1988; Gutknecht \& Keys, 1993), especially when the surviving workers know they have not been laid off (Brockner, 1988).

As employees are dismissed from a work environment, the remaining employees may positively or negatively characterize the downsizing depending on their gain or loss of connections to network resources they view as valuable (Shah, 2000; Susskind et al., 1998). In sum, downsizing is a prevalent organizational change practice that normally leads to 
considerable changes in an organization's structure and is commonly framed by surviving employees in a negative light (Brockner et al., 1993).

Research on downsizing has shown that (a) observable physical reconfigurations to work groups are likely to have considerable impact on employee attitudes and performance (Cummings \& Cross, 2003), (b) a considerable number of often-cited downsizing studies are laboratory versus field based (e.g., Brockner, Davy, \& Carter, 1985; Brockner, Grover, Reed, Dewitt, \& O'Malley, 1987) that cannot capture the true experience of a downsizing, and (c) it is unclear how organizational members cope with lost linkages, role and positional changes, and the need to form new linkages following downsizing events (Shah, 1998, 2000; Susskind et al., 1998). Although the research noted above highlights the attention devoted to organizational downsizing and its effects, Kozlowski et al. (1993) and Mishra and Spreitzer (1998) argued that our understanding of downsizing-related phenomena would be improved by additional crosslevel, longitudinal, field-based investigations. Following that call, in this investigation I examine how a downsizing event affects downsizing survivors' communication relationships and attitudes across the postdownsizing environment, considering individual perceptions and attitudes along with network level metrics.

\section{Communication Networks and Downsizing}

Research on communication network structure has shown that (a) communication network patterns are related to network members' organizational commitment and role ambiguity (Hartman \& Johnson, 1989), (b) individuals' power and centrality are localized in organizational networks (Brass \& Burkhardt, 1992, 1993) and are influenced by positional and demographic characteristics (Ibarra, 1992, 1993, 1995; Ibarra \& Andrews, 1993), (c) longitudinal 
changes in network relationships have a unique influence on network members' perceptions of uncertainty and openness to change following a downsizing event (Susskind et al., 1998), and (d) changes to friendship and advice networks lead to unique affective responses among downsizing survivors in the postdownsizing environment (Shah, 2000).

Although organizations typically divide their members into formal departments or functional groups, a variety of informal communication links exist within and between formal work groups (Hartman \& Johnson, 1990; Podolny \& Baron, 1997). As noted by Shah (2000), organizational members maintain task and social relationships with other members at varied hierarchical levels that make up the network in an organization. Ibarra and Andrews (1993) indicated that network interaction can influence individual perceptions and attitudes through either positional characteristics, such as status, or through specific network relationship content, such as friendship or advice.

Shah (2000) examined the network implications of downsizing and found that the loss of survivors' friendship ties were not easily replaced and generally led to negative affect in the postdownsizing environment. Furthermore, Shah reported that 6 months following a downsizing friendship and advice networks were influenced differently, noting that friendship network centrality decreased and advice network centrality increased. These findings suggest that employees' adjustments to a new postdownsizing network are tied in part to organizational performance following a downsizing, and it is likely that the flow of communication and the general effectiveness of communication during and following a downsizing event influence survivors' perceptions and attitudes (Caplan \& Teese, 1997).

As the network changes, individuals in the network will likely rely in part on their transactive memory to help them process their information needs in the postdownsizing 
environment. Transactive memory is a collection of information that exists in an organizational setting where members are aware of shared and unique information held by others that are needed for work functioning (Hollingshead, 2001; Wegner, 1987).

Given our current knowledge of downsizing and communication networks it is reasonable to state that after an organizational downsizing the organization's communication network fluctuates as members are removed and surviving network members adjust to the postdownsizing environment. Individuals will reconfigure their communication and interaction networks to accommodate the loss and/or addition of communication linkages (Shah, 2000; Susskind et al., 1998), eventually leading to a reconfigured postdownsizing network. This is a key adjustment factor for downsizing survivors to work through. These adjustments will likely be facilitated, in part, by transactive memory, where members begin to understanding and process who holds what information and how it is important to operational functioning (Hollingshead, 2001).

In the model presented as Figure 1, I propose that changes in information flow and employees' perceptions of information adequacy across a downsizing event influence survivors' turnover intentions in the postdownsizing environment. In the model, the vertical arrows characterize the proposed relationships between changes in centrality, changes in perceptions of information adequacy, and turnover intentions across the pre- and first postdownsizing periods (first column) and the first and second postdownsizing periods (second column). Last, the horizontal arrows depict the anticipated autocorrelation among the centrality, perceptions of information adequacy, and turnover intentions variables. 


\section{Network Centrality}

Centrality, as presented by Freeman (1979), can be described in terms of (a) degree- - the number or percentage of individuals a network member is connected to, (b) closeness- the reach an individual has in a network based on the minimum distance it takes for a member to contact all other members in the network, and (c) betweenness - the extent to which a network member mediates other network relationships and controls the flow of information in a network.

All three types of centrality overlap to some extent, with each type capturing slightly different relationships and relevant outcomes within a network (Feeley, Susskind / Downsizing Survivors' 2000; Mullen, Johnson, \& Salas, 1991). Feeley (2000) and Feeley and Barnett (1997) reported through tests of the erosion model of employee turnover that workers on the periphery of the organizational network (i.e., less central members) indicate that they are more likely to leave the organization when asked about their turnover intentions. Downsizing will likely affect

each type of centrality as members are removed from the network and existing relationships are reconfigured to accommodate the changes. However, each type of centrality will increase or decrease for members depending on how their specific contacts are affected by the downsizing. Although changes to downsizing survivors' number of network connections (degree centrality) and the distance between those connections (closeness centrality) are not trivial, changes to network members' betweenness centrality seem to be more directly related to perceptions of information adequacy than either degree or closeness centrality because of its unique relationship with information flow and control (Shah, 2000).

As betweenness centrality changes for a particular network member, the amount of information that the individual controls changes as well. This is consistent with the proposition that direct, unmediated connections to others in a network tend to reduce tension and pressure 
(Baldwin, Bedell, \& Johnson, 1997) particularly for the gatekeepers of information in the network (Krackhardt, 1992). In addition, betweenness centrality is often considered the strongest measure of network involvement as high levels of betweenness centrality is associated with the brokerage of information and relationships across a network (Krackhardt, 1992) and satisfaction with team dynamics and leadership (Mullen, et al., 1991). Although degree and closeness centrality each assess the extent of connection and proximity to others in the network, betweenness centrality assesses the extent to which a particular network member mediates the flow of information and contact (Cross \& Cummings, 2004; Feeley, 2000; Mullen et al., 1991).

Therefore, changes in betweenness centrality can produce either a positive or negative outcome for downsizing survivors depending on their control of information and contacts that are gained, lost, or maintained through the network (Susskind et al., 1998).

\section{Perceptions of Information Adequacy}

Regardless of hierarchical level in an organization, workers require information to perform their work-related duties. The perception of not receiving sufficient information can influence employees' willingness to participate in organizational change or future development activities (Casey, Miller, \& Johnson, 1997; Miller, Johnson, \& Grau, 1994). Morrison (2002) pointed out that a need for information under conditions of organizational change is influenced by contextual and individual factors. In particular, contextual issues such as ambiguity or performance pressure relative to the new organizational structure, and individual factors such as a tolerance for uncertainty or a need for control, are likely to influence survivors' perceptions of information adequacy. Synder and Morris (1984) also emphasized the importance of information 
sharing within work groups and the quality of superior-subordinate communication as elements important to organizational functioning.

This contention has been empirically supported by Cummings and Cross (2003) who showed that when holding levels of communication constant, leaders in an organizational network (i.e., higher in centrality) who were in better positions to broker information (i.e., higher levels of structural holes) negatively influenced performance in the network. As members control more information, they can use that information to control the formation of new relationships and interaction in the network. This suggests that the flow of information influences outcomes when individuals are in a position of brokerage and are able to control gaps (structural holes) in the network.

Although perceptions of information adequacy vary among layoff survivors, downsizing affects betweenness centrality and hence information flow in the communication network and likely leads survivors to experience shifts in perceptions of work-related information adequacy in the postdownsizing environment.

In the postdownsizing environment, access to information is a key resource. It should be noted, however, that changes to downsizing survivors' networks can occur in many ways. In addition to losing or gaining contacts as a result of shifts in personnel, individuals can be promoted, demoted, or moved, which will affect their power and position, their reporting relationships, and ultimately their need for and access to work-related information.

In the current study, the primary focus is on the relationship between betweenness centrality and perceived information adequacy; it is based on the premise that jobrelated information is channeled and distributed through the headquarters of the company for employees to perform their jobs. Information is shared and exchanged through communication and 
interaction with coworkers and superiors and is augmented by other sources the headquarters supports—-such as the field operations, vendors, and guests.

Information sources in the postdownsizing network can be classified relative to source expertise and accessibility (Morrison \& Vancouver, 2000). Individuals will be aware of special or unique information held by others and may attempt to tap into those resources to enhance their functioning or position in the organization (Hollingshead, 2001). Highly central network members are likely to be the most accessible; however, the value that they bring to and or broker in the postdownsizing network may vary considerably. Members losing network centrality are likely to show decreases in their perceptions of information adequacy and be more aware of information gaps and resource losses brought about by the downsizing. Survivors may need to spend considerable time restoring lost connections in their networks and building trust before their perceptions of information adequacy return to predownsizing levels (Shah, 2000). Likewise, downsizing survivors may acquire a better network position following the downsizing and find access to and control of information that was not available to them before the downsizing. Following Feeley's (2000) reformulation of the erosion model of employee turnover (Feeley \& Barnett, 1997) he found that when considering network structure (opposed to strictly attitudinal measures) organizational commitment was not as strong of a deterrent to turnover intentions as previously believed (Feeley \& Barnett, 1997; Tett \& Meyer, 1993). He then suggested that alternative mediators between network structure and turnover intentions be explored. The addition of perceived information adequacy as a mediating variable between network centrality and turnover intentions offers an attempt to fulfill his call. Therefore, I propose a positive relationship exists between changes in centrality and changes in perceptions of information adequacy. 
Hypothesis 1: Changes in betweenness centrality are related to changes in perceptions of information adequacy across the pre- and first postdownsizing periods.

Hypothesis 2: Changes in betweenness centrality are related to changes in perceptions of information adequacy across the first and second postdownsizing periods.

Although the propositions regarding how changes in betweenness centrality are related to changes in information adequacy over time seem straightforward, the expected autocorrelation among changes in centrality and changes in information are less so. Individuals who experience changes in centrality and information adequacy from the predownsizing period to first postdownsizing period — as either gains or losses—are less likely to experience similar shifts in subsequent periods as they adapt to the new postdownsizing network (Stefanone, 2004; Susskind et al., 1998).

Survivors who report gains in centrality between the predownsizing and first postdownsizing periods are not likely to note similar gains between the first postdownsizing and second postdownsizing periods because the initial downsizing reconfiguration has improved their position, or at least increased their access to or control of information. However, those who report losses in centrality in the first postdownsizing period will most likely need to make adjustments to their network to restore access to pieces of the information they lost. This will lead to gains in centrality in the second postdownsizing period for those who showed losses in the first postdownsizing period. These anticipated cross-lagged gains in the second postdownsizing period are created from the gains in information flow realized by their peers in the first postdownsizing environment (Stefanone, 2004; Susskind et al., 1998). This should result in a negative autocorrelation among the change scores for centrality and information adequacy. Consequently, I hypothesize: 
Hypothesis 3: Changes in betweenness centrality at the first postdownsizing period will be negatively related to changes in betweenness centrality at the second postdownsizing period.

Hypothesis 4: Changes in information adequacy at the first postdownsizing period will be negatively related to changes in information adequacy at the second postdownsizing period.

\section{Changes Over Time and Turnover Intentions}

As noted by Amburgey, Kelly, and Barnett (1993), "organizational change can be both disruptive and adaptive" (p. 51). Downsizing is a particularly disruptive organizational event that challenges survivors to restore a sense of order to their work environment. Job-related uncertainty and chaos in the postdownsizing environment are likely to cause individuals to realign their patterns of network interaction and information flow (Susskind et al., 1998). An individual's desire to end an employment relationship is normally framed as a set of psychological responses to specific organizational conditions, typically including withdrawal behaviors ranging from daydreaming to the physical act of quitting (Kraut, 1975).

Evaluations of turnover intentions generally indicate a negative relationship between turnover intentions and job affect such as organizational commitment and job satisfaction (Davy, Kinicki, \& Scheck, 1991; Tett \& Meyer, 1993). Although downsizing represents involuntary turnover for those dismissed, survivors' turnover intentions in a postdownsizing environment are likely to be influenced by a number of factors, most notably unresolved job tension (Abelson, 1987) and lack of trust in management following the downsizing (Mishra \& Spreitzer, 1998). 
Survivors are more likely to consider voluntary turnover when their access to important job-related information worsened as a result of the downsizing and they are not able to restore a sense of order into their work life after the downsizing. This does not have to be directly related to network position or centrality per se; however, shifts in network structure are likely to influence future actions and adaptive behavior (Podolny \& Baron, 1997). As noted by Rice (1993) and Feeley and Barnett (1997), social influence theory would suggest that workers' perceptions and processing of organizational events (such as a downsizing event) are influenced by cues and communication from coworkers to whom they are directly connected. Therefore, based on social influence theory survivors' doubts about staying with organization in the immediate postdownsizing environment (or those who plan to stay) are likely to spill over to subsequent time periods.

Hypothesis 5: Turnover intentions at the first postdownsizing period (T2) will be positively related to turnover intentions at the second postdownsizing period (T3).

Although data exists to describe how downsizing survivors are likely to react to equity issues surrounding a downsizing (cf., Brockner et al., 1993; Brockner et al., 1997; Davy et al., 1991; Mishra \& Spreitzer, 1998), little information exists to describe how survivors react to downsizing-induced changes in their communication networks, and how those changes influence survivors' work-related perceptions and attitudes (Shah, 2000). Although information-sharing mechanisms have been shown to help further employees' ability to complete work-related activities and enhance feelings of mutual trust and commitment toward the organization (cf., Lawler, 1986; Meyer, Allen, \& Smith, 1993; Rodwell, Kienzle, \& Shadur, 1998), not receiving adequate levels of pertinent work-related information has been shown to negatively influence 
downsizing survivors' certainty about their career futures (Casey et al., 1997; Johnson, Bernhagen, Miller, \& Allen, 1996; Mishra \& Spreitzer, 1998), is believed to negatively affect levels of commitment to the organization (Feeley \& Barnett, 1997), and is connected to turnover intentions (Abelson, 1987; Feeley \& Barnett, 1997; Mishra \& Spreitzer, 1998). Therefore, employees' perceptions of information adequacy are particularly important during times of uncertainty when employees have an enhanced need for information (Morrison \& Vancouver, 2000).

It could be expected then that decreases in information adequacy are related to higher levels of turnover intentions because the loss of needed work-related information will likely prompt survivors to reevaluate their current employment relationship and their desire to remain employed in the postdownsizing environment. This is likely to be the most severe for survivors when the change in information flow influences their ability to successfully perform their workrelated duties (Morrison \& Vancouver, 2000) and raises questions about their organizational future as downsizing survivors (Casey et al., 1997; Johnson et al., 1996; Mishra \& Spreitzer, 1998).

Hypothesis 6a: Increases in perceived information adequacy at the first postdownsizing period will be negatively related to turnover intentions at the first postdownsizing period.

Hypothesis 6b: Increases in perceived information adequacy at the second postdownsizing period will be negatively related to turnover intentions at the second postdownsizing period. 


\section{Method}

\section{Procedure and Participants}

One hundred and thirty employees working in an international hotel company's corporate office were surveyed prior to and following an organizational downsizing. Employees' network relationships, perceptions, and attitudes were first measured 60 days prior to the scheduled downsizing (T1), and then measured 60 days (T2) and 120 days (T3) following the downsizing event. At all three data collection periods the participants completed a communication network questionnaire and an attitude questionnaire; the participants provided demographic information at T1 only. The data collection timeframe and processes were discussed, negotiated, and ultimately agreed on by the company leadership to minimize potential disruptions beyond those created by the downsizing itself, while still allowing for a realistic longitudinal research design to answer the questions proposed in the study.

The participants at $\mathrm{T} 1$ were $56 \%$ male, between ages 20 and 57 years $(\mathrm{M}=33.42)$ and varied in their tenure within the organization. Approximately 12\% $(\mathrm{n}=17)$ had been employed for 1 year or less, $23 \%(n=30)$ had been employed between 1 and 2 years, $36 \%(n=46)$ had been employed between 2 and 5 years, and 29\% $(n=37)$ had been employed for 5 years or greater. At each data collection point, participants fully represented the accounting, finance, marketing, rooms, facilities engineering, administration, and personnel departments. The seven departments surveyed represented $78 \%$ of the population from the headquarters excluding 37 members who did not participate in the current study: 9 from the legal department, 12 from the customer support unit, 12 from the foodservice management unit, and the 8 top-level managers (such as the CEO, $\mathrm{CFO}$, and the senior vice presidents). Of the surviving employees from the sample, two employees missed one questionnaire administration (one at T2 and one at T3). 
Initially, one additional participant was included in sample but left the company prior to the questionnaire administration at $\mathrm{T} 1$. The remainder of the sample completed and returned the questionnaire at all three time periods and provided a final valid sample of $\mathrm{N}=91$ across all three periods using listwise deletion. All of the study's participants were assured strict confidentiality in their responses and guaranteed that their names or the name of the company would not be used in any report of the data.

The focus of the organization's downsizing was to remove notable redundancy from the corporate headquarters. The general corporate structure and reporting relationships remained consistent with the predownsizing structure, framing this downsizing effort as a reduction in workforce rather than a restructuring. The downsizing announcement was made public 30 days prior to its implementation. At that time, the affected employees were counseled, and the layoffs were effectuated in three ways. First, several of the selected employees were eligible for "early retirement" and were presented with a retirement incentive. Second, several employees were given the option of taking positions at the operational level within the company, while the remaining employees were dismissed without additional options. Each affected employee was given 1-month severance pay in addition to the 30-day notice. The 33 downsized employees were $52 \%$ male and $48 \%$ female, between ages 20 and 54 years $(M=33.58)$, with $12 \%(n=4)$ employed for 1 year or less, 30\% ( $\mathrm{n}=10)$ employed between 1 and 2 years, $33 \%(\mathrm{n}=11)$ employed between 2 and 5 years, and $24 \%(n=8)$ employed for 5 years or greater.

Following the downsizing, the 97 survivors were 58\% male, between ages 20 and 57 years $(M=32.24)$. The surviving participants also varied in their tenure within the organization with $13 \%(n=13)$ employed for 1 year or less, $21 \%(n=20)$ employed between 1 and 2 years, 
$36 \%(\mathrm{n}=35)$ employed between 2 and 5 years, and 30\% $(\mathrm{n}=29)$ employed for 5 years or greater.

\section{Measurement}

Communication network relationships. Communication network data were gathered to assess each participant's work-related contacts. The network questionnaire asked the participants to specify the people you communicate with in the corporate office on a regular basis during the course of a normal workweek. Each participant was given an alphabetized directory containing the names of the corporate employees in the sample listed by department. The participants were given additional oral instructions prior to filling out the directory to report only relationships related to the performance of their jobs with the hopes of addressing their instrumental relationships, rather than their expressive relationships. The likelihood of collecting strictly instrumental relationships in a questionnaire such as this is difficult as many instrumental and expressive relationships overlap (Shah, 2000); however, the focus of this data collection was on instrumental relationships based on organizational constraints imposed on the data collection process. This self-report data collection technique is one of several available to measure communication network relationships (Monge \& Contractor, 1987) and represents a preselected, fixed respondent set, based on a nominal approach to defining boundaries for the sample (Laumann, Marsden, \& Prensky, 1983).

A symmetrical $130 \times 130$ matrix was created to represent the predownsizing network with cell entry $X_{i j}$ set to 1 if either actor in the dyad reported a relationship or set to 0 if both participants acknowledged no relationship. Similarly a $97 \times 97$ matrix was created to represent both postdownsizing networks. There was a high level of reported agreement among the network 
relationships in each of the three time periods, where for dyads $X_{i j}$ and $X_{j i}$ recognized the same relationship $98.32 \%$ of the time at $\mathrm{T} 1,96.71 \%$ of the time at $\mathrm{T} 2$, and $96.07 \%$ of the time at $\mathrm{T} 3$. This high level of symmetry reported among the dyads was likely facilitated by the use of the departmentalized directory to collect the data.

Assessing changes in network centrality. Betweenness centrality was calculated using UCINET version 5.3 (Borgatti, Everett, \& Freeman, 1999) by determining the extent to which each network member appeared on the shortest link between two different actors. The normalized centrality values were used to correct for size differences between the pre- and postdownsizing networks, and only the responses from the 97 survivors were used from the three data collection periods.

To identify changes in downsizing survivors' betweenness centrality in the network, I calculated two change scores for each participant. The first change score was derived by subtracting the $\mathrm{T} 1$ betweenness centrality scores from $\mathrm{T} 2$ scores capturing the change in centrality from the predownsizing period to the first postdownsizing period. Similarly, the second change score was derived by subtracting the $\mathrm{T} 2$ betweenness centrality scores from $\mathrm{T} 3$ scores, representing each participant's change in centrality from the first postdownsizing period to the second postdownsizing period. A positive change score in both cases indicated a postdownsizing increase in centrality. Reliability coefficients were not calculated for the change scores because they were derived from a single-item indicator.

Survey measurement. Survey measures evaluated the participants' perceptions of information adequacy and turnover intentions using a 5-choice Likert-type metric by asking the participants to indicate their level of agreement with the questions (strongly agree, agree, neutral, disagree, and strongly disagree). Information adequacy was measured using a 4-item instrument 
developed by Miller et al. (1994). A sample item from this measure is: "I am thoroughly satisfied with the information I receive about what's going on at this company." The reliability of the measure was $\alpha=.83, \alpha=.86, \alpha=.96$, at T1, T2, and T3, respectively. Similar to the centrality changes scores calculated, the T1 scores were subtracted from $\mathrm{T} 2$ scores capturing the change in perceptions of information adequacy from the predownsizing period to the first postdownsizing period, and the second change score was derived by subtracting the T2 scores from T3 scores capturing the change in perceptions of information adequacy from the first postdownsizing period to the second postdownsizing period. A positive score represented an increase in perceived information adequacy in both cases. The reliability of the first change score was $\alpha=$ .84 , and the reliability of the second change score was $\alpha=.89$. Turnover intentions were assessed using a 2-item measure adapted from Hackman and Oldham (1975). A sample item from this measure is: "I frequently think of quitting this job." The reliabilities of the turnover intentions measure were $\alpha=.85$ and $\alpha=.77$ at T2 and T3, respectively. Change scores were not used for the turnover intentions variable.

\section{Composition Variables}

Prior network research has identified a number of member attributes, such as age, sex, and educational level (cf., Ibarra, 1992, 1993, 1995; Ibarra \& Andrews, 1993; Shah, 2000) and job-related variables, such as tenure, hierarchical level, and departmental affiliation (Brass \& Burkhardt, 1992, 1993; Ibarra, 1993; Shah, 2000) as important influences on network relationships and outcomes. To account for the potential influences from these factors I examined them along with variables presented in Figure 1. Based on the findings of Ibarra and Andrews (1993), it might be expected that workers, who have higher levels of education, hold 
higher level positions, are older, and have more time on the job are more likely to be central in instrumental networks. It should be noted that males also tend to hold higher level positions in organizations, are likely to be more central, and hence, are more powerful in instrumental networks (Ibarra, 1992, 1995). Last, the number of members downsized from each department may also influence survivors' perceptions of information flow and subsequent work-related attitudes in the postdownsizing environment.

To control for these potential influences on centrality, information adequacy, and turnover intentions at $\mathrm{T} 2$ and $\mathrm{T} 3$ in the model: (a) sex was represented as a dummy variable with male $=1$, female $=0$; (b) education was represented categorically ranging from a low of "some high school" $=1$ to a high of "graduate degree" $=7 ;$ (c) hierarchical level in the company was represented categorically with "managerial level" $=3$, "staff level" $=2$, and "clerical level" $=1$; (d) tenure was represented categorically as less than 1 year $=1,1$ to 2 years $=2$, and greater than 2 years $=3$; (e) a score was calculated to represent the percentage of employees downsized in each department (current number minus prior number divided by prior number); (f) each of the seven departments were entered into the equation as a dummy variables to see if any particular department's influence was notable; and (g) age was measured continuously. The seven control variables (sex, education, hierarchical level, tenure, departmental change, department affiliation, and age) were entered into six hierarchical regression equations: once each with changes in centrality as the dependent variable at $\mathrm{T} 2$ and $\mathrm{T} 3$, once each with changes in information adequacy as the dependent variable at $\mathrm{T} 2$ and $\mathrm{T} 3$, and once each with turnover intentions as the dependent variable at $\mathrm{T} 2$ and $\mathrm{T} 3$. Results of the preliminary regression analyses indicated that age, hierarchical level, and departmental influence were significant influences in the model. First, age was a significant influence on changes in centrality at $\mathrm{T} 2, \beta=.44, \mathrm{t}(1)=2.94, \mathrm{p}=.004$. 
Next, hierarchical level was a significant influence on changes in centrality at $\mathrm{T} 2, \beta=-.32, \mathrm{t}(1)=$ $2.53, \mathrm{p}=.01$, turnover intentions at $\mathrm{T} 2, \beta=.28, \mathrm{t}(1)=2.03, \mathrm{p}=.05$, and turnover intentions at $\mathrm{T} 3, \beta=-.44, \mathrm{t}(1)=-3.49, \mathrm{p}=.001$. An affiliation with the engineering department was significantly related to changes in information sufficiency at $\mathrm{T} 2, \beta=.31, \mathrm{t}(1)=2.36, \mathrm{p}=.02$, changes in turnover intentions at $\mathrm{T} 2, \beta=-.29, \mathrm{t}(1)=-2.28, \mathrm{p}=.03$, and turnover intentions at $\mathrm{T} 3, \beta=-.25, \mathrm{t}(1)=-2.02, \mathrm{p}=.05$. Last, an affiliation with the marketing department was significantly related to turnover intentions at $\mathrm{T} 2, \beta=-.26, \mathrm{t}(1)=-2.10, \mathrm{p}=.04$. The standardized results from the regression analyses are presented in Table 1. The noted significant relationships from the control variables were added to and tested the model presented as Figure 2.

\section{Analyses}

Least squares path analysis (Hunter \& Hamilton, 1995) was used to test the latent path model presented as Figure 1. Model adequacy was assessed based on the recommendations that: (a) global $\chi 2$ tests for the sum of squared error for the model be nonsignificant at the $p>.75$ level (Hayduk, 1996); (b) each link be tested for significance by calculating a confidence interval around the observed coefficients (Loehlin, 1998); and (c) sampling error analyses be applied to each unspecified link in the model to ensure that the hypothesized model did not exclude any relevant links from consideration in the model (Loehlin, 1998).

To support the least squares analyses described above and to yield additional fit indices, the model presented as Figure 2 was tested using a maximum likelihood approach with LISREL 8.12a (Jöreskog \& Sörbom, 1993). To test the path model I followed Hayduk’s (1987) recommendations. By default, the error terms were permitted to correlate and no other relationships other than those specified in the path diagram were permitted to correlate in the 
structural analyses. To adjust for measurement error in the scale values within the path model, the paths from the latent variables to the indicators were set to the square root of the scale reliability. In addition, the error variance was set to equal the variance of the scale multiplied by one minus the reliability. These procedures fix the proportion of error variance assigned to each factor based on the scale reliabilities and the relevant variance associated with each factor (Hayduk, 1987). To supplement the sampling assessment of fit using PATHE (Hunter \& Hamilton, 1995), the Comparative Fit Index (CFI) and root mean square residual (RMR) fit statistics are reported.

\section{Results}

The path coefficients and their standard errors are reported in Figure 2, the descriptive statistics and correlations of the final scale variables are reported in Table 2, and the descriptive statistics and correlations for the primary variables not converted to change scores are reported in Table 3.

As detailed below, the initial path analyses revealed that the hypothesized model fit the data very well, $\chi 2(24)=13.58, \mathrm{p}=.95, \mathrm{CFI}=.95, \mathrm{RMR}=.05$, with six of the seven hypothesized path linkages identified as statistically significant in the model. Moreover, sampling error analyses revealed no misspecifications in the model.

The path between changes in centrality at T2 and changes in information adequacy at T2 was significant (path coefficient $=.29, p<.01$ ), indicating that changes in centrality between the pre- and postdownsizing networks influenced changes in the downsizing survivors' perceptions of information adequacy between the pre- and postdownsizing networks (Hypothesis 1 supported). Hypothesis 2 was not supported because the path between changes in centrality at 
$\mathrm{T} 3$ and changes in perceived information adequacy at $\mathrm{T} 3$ was not significant $($ path coefficient $=$ .09). This finding suggests that shifts in centrality between the two postdownsizing networks were not connected to changes in the survivors' perceptions of information adequacy during the same time periods. The hypothesized autocorrelation between changes in centrality at T2 and T3 was negative and significant showing a moderate negative relationship (path coefficient $=-.32, p$ $<.001$ ), indicating that changes in centrality were inversely related across the postdownsizing environment (Hypothesis 3 supported). Likewise, the hypothesized autocorrelation between changes in perceived information adequacy at $\mathrm{T} 2$ and $\mathrm{T} 3$ was significant, showing a strong negative relationship (path coefficient $=-.69, p<.001$ ), indicating that changes in perceptions of information adequacy were also inversely related across the postdownsizing environment (Hypothesis 4 supported). Turnover intentions at $\mathrm{T} 2$ were moderately related to turnover intentions at $\mathrm{T} 3$ (path coefficient $=.37, p<.05$ ), indicating that network members' turnover intentions at T2 influenced turnover intentions at T3. Last, Hypothesis 6a and Hypothesis 6b were supported as changes in perceptions of information adequacy at T2 and T3 were negatively and significantly influenced turnover intentions (path coefficient $=-.78, p<.001$ and path coefficient $=-.68, p<.001$, at T2 and T2, respectively). More specifically, this relationship changed over time with losses in information adequacy $(\mathrm{M}=-1.38)$ leading to higher levels of turnover intentions $(\mathrm{M}=3.48)$ at $\mathrm{T} 2$ and increases in information adequacy $(\mathrm{M}=1.57)$ leading to lower levels of turnover intentions $(\mathrm{M}=1.85)$ at $\mathrm{T} 3$.

\section{Post Hoc Test of an Alternative Model}

The model presented as Figure 2 was modified to examine the direct effect of changes in betweenness centrality on turnover intentions at $\mathrm{T} 2$ and $\mathrm{T} 3$. This was accomplished by reversing 
the positions of the centrality and information adequacy variables in the model. The model did not fit the data well, $\chi^{2}(8)=33.22, p<.001, \mathrm{CFI}=.56, \mathrm{RMR}=.19$. The sampling error analyses revealed that the lack of fit in the model was due primarily to an unspecified link between changes in information adequacy at T2 and T2 turnover intentions. It should be noted that the path between $\mathrm{T} 2$ betweenness centrality and T2 information adequacy $(\beta=.76, p<.001)$ was significant in the model $(\beta=-.39, p<.01)$, in addition to the autocorrelation between the changes in centrality and information adequacy at $\mathrm{T} 2$ and $\mathrm{T} 3(\beta=-.71, p<.001$ and $\beta=-.28$, $p<.01)$. The examination of this ill-fitting post hoc model provides support for the causal ordering and presentation of hypothesized model presented as Figure 2. Likewise, an additional longitudinal model using the primary associations among the variables (sans the change scores) was tested and revealed that the model presented as Figure 2 represents the best fit to the data. This set of additional analyses is not included here because of space constraints but is available from the author on request.

\section{Discussion}

A primary goal of the current investigation was to describe how individuals react to downsizing-induced changes in information flow across a downsizing event. The current investigation connects downsizing-induced changes in communication networks to downsizing survivors' perceptions and reactions over time and offers new insight into the interpersonal mechanisms that shape attitudinal variables and behavioral intentions across a downsizing event.

The current study revealed that changes to downsizing survivors' network centrality in the immediate postdownsizing environment were positively related to changes in perceptions of information adequacy and changes in information adequacy were negatively related to turnover intentions consistently across the postdownsizing environment. The model presented as Figure 2 
represented the data quite well, tapping into reactions across three different time periods during 6 months within an organization's history. Below I discuss the results of the study as it relates to support for the hypotheses, its limitations, and its pragmatic implications.

\section{Support for the Hypotheses}

$\Delta$ Centrality to $\Delta$ perceived information adequacy. Although a positive relationship existed between changes in centrality and changes in information sufficiency in both postdownsizing periods, the relationship was only significant in the model at $\mathrm{T} 2$. The findings connected changes in information flow to survivors' perceptions of work-related perceived information adequacy; with changes in centrality being related to changes in perceived information adequacy only in the time period immediately following the downsizing. The nonsignificant relationship noted from $\mathrm{T} 2$ to $\mathrm{T} 3$ suggests that when a postdownsizing network begins to stabilize, adjustments to network relationships following the initial downsizing have a less significant influence on survivors' perceptions of information adequacy and highlights the difference between downsizing-induced changes and changes made after several months have passed in the postdownsizing environment.

Very small changes occurred to network density and average degree over time as well, indicating a tightening of the network over time as hypothesized. This set of findings is further supported by network descriptive statistics calculated using Sienna version 2.4b (Stokman, van Duijn, \& Snijders, 2006) that detail the changes in the network over time (see Table 4).

Based on the dyad counts, the majority of the losses took place from T1 to T2; however, there was an increase of unreciprocated ties from T2 to T3. From T1 to T2, 81 relationships were added $(0 \rightarrow 1)$, whereas from T2 to T3, 63 relationships were added $(0 \rightarrow 1)$. From T1 to T2, 54 
relationships were lost $(1 \rightarrow 0)$, whereas from T2 to T3, only 37 relationships were lost $(1 \rightarrow 0)$. Network stabilization after T2 is also evidenced by the reduction in standard deviation and the smaller $\mathrm{t}$ statistic $(\mathrm{T} 1 \rightarrow \mathrm{T} 2:$ average $=2.072, \mathrm{SD}=18.52, \mathrm{t}$ statistic $=.11 ; \mathrm{T} 2 \rightarrow \mathrm{T} 3:$ average $=$ $1.068, \mathrm{SD}=15.74, \mathrm{t}$ statistic $=.06)$, as good convergence is evidenced by the $\mathrm{t}$ statistic being close to zero (Stokman et al., 2006). Last, although the correlations calculated using the quadratic assignment procedure (Borgatti et al., 1999) among the networks over time are strong, the results show a stronger correlation between $\mathrm{T} 2$ and $\mathrm{T} 3(\mathrm{r}=.92)$ compared to the other combination of time periods considering $\mathrm{T} 1$ and $\mathrm{T} 2$ and $\mathrm{T} 1$ and $\mathrm{T} 3(\mathrm{r}=.89, \mathrm{r}=.84$, respectively).

$\Delta$ Perceived information adequacy to turnover intentions. Network members' changes in perceived information adequacy were significantly related to turnover intentions in both postdownsizing periods. At T2, survivors who reported decreases in perceived information adequacy reported a higher level of turnover intentions compared to their peers who reported gains in perceived information adequacy over the same time frame. It is possible that those who gained contacts in the postdownsizing environment had greater access to support processes that, in turn, lowered their negative perceptions toward their job situation. Conversely, survivors who reported decreases in perceived information adequacy at T2 reported a higher level of turnover intentions indicating that the loss of contacts led them to reevaluate their current employment situation.

Individual reactions to the downsizing were generally negative 2 months after the event; however, most survivors' reactions returned to predownsizing levels after 4 months. Consistent with prior downsizing studies (e.g., Brockner et al., 1997; Davy et al., 1991), downsizing is expected to produce negative reactions among survivors, and employees' perceptions and 
attitudes ought to remain negative until a sense of security and stability emerges in the postdownsizing environment (Mishra \& Spreitzer, 1998). After all, a downsizing can bring the loss of friends and resources and create obstacles to work productivity through the loss of social capital (Burt, 2000; Susskind et al., 1998).

Although the findings indicated that survivors' perceptions of their work environment would recoup given sufficient adjustment time, this rebound may be rooted in employees' psychological dissonance created by surviving the downsizing (Mishra \& Spreitzer, 1998). Survivors may come to terms with feelings of betrayal (Gutknecht \& Keys, 1993) and the loss of resources and colleagues (Susskind et al., 1998) by reasoning that their work setting has improved and opportunities for professional and corporate growth are greater than before the downsizing (Mishra \& Spreitzer, 1998; Podolny \& Baron, 1997). For instance, perceptions of support from coworkers, supervisors, and the organization as a whole may shape employee reactions under conditions of change (Brockner et al., 1997; Krackhardt \& Porter, 1985, 1986; Salancik \& Pfeffer, 1978). In times of uncertainty, workers may rely on the unique knowledge base of their peers (Hollingshead, 2001) in addition to the support from their coworkers and supervisors to regain a sense of control over their work domain and aid in their adjustment to their changing work environment (Davy et al., 1991). Future research should determine the role of coworker and supervisory support in the postdownsizing adjustment process and how it relates to network configurations and resulting attitudes over time.

Changes in centrality across time. The downsizing had temporal effects on the survivors' network centrality. First, the centrality change scores at T2 and T3 showed a negative test-retest correlation over time $(\mathrm{r}=-.32, p<.01)$, indicating that the direction of changes in centrality in one postdownsizing period was inversely related to changes in the other. Survivors, who showed 
losses in centrality immediately following the downsizing apparently adjusted to those changes, reformed their network based on the new conditions, and showed gains in centrality thereafter. Likewise, those survivors who initially showed gains in centrality at T2 adjusted their network after the initial downsizing period, and most likely forfeited portions of their newly acquired centrality to accommodate the need for change among those who lost centrality in the previous time period. Second, the magnitude of change in centrality at T2 ranged from -2.34 to 9.74 , whereas at $\mathrm{T} 3$ the magnitude of change in centrality ranged from -3.57 to 3.01 , showing a smaller range of changes overall indicating that the network had substantially stabilized. This set of findings also highlights the difference between voluntary and involuntary changes to survivors' networks. The changes from $\mathrm{T} 1$ to $\mathrm{T} 2$ could be characterized as involuntary as employees were downsized from the network. At that point in time the downsizing required some level of adjustment and realignment for most of the survivors. At T3, however, no personnel were involuntarily removed from the network, and any changes made by network members were likely made to improve their postdownsizing position based on their perceived work-related needs in the postdownsizing network.

Changes in perceived information adequacy across time. Like centrality, the perceived information adequacy change scores at $\mathrm{T} 2$ and $\mathrm{T} 3$ showed a negative test-retest correlation $(\mathrm{r}=-$ $.61, p<.001)$, indicating that increases in one postdownsizing period were associated with decreases in the other. Survivors' reported levels of perceived information adequacy decreased overall in the immediate postdownsizing period with perceptions of information adequacy shifting an average of -1.38 points from $\mathrm{T} 1$ to $\mathrm{T} 2$ but returning to predownsizing levels with a positive change score of 1.57 from $\mathrm{T} 2$ to $\mathrm{T} 3$ restoring a general sense of information adequacy among the survivors as time progressed after the downsizing. 
Changes in turnover intentions across time. Unlike centrality and perceived information adequacy, turnover intentions showed a negative and nonsignificant test-retest correlation at T2 and T3 $(\mathrm{r}=-.05, \mathrm{~ns})$, indicating that survivors' turnover intentions were not consistently related over time when considering the zero-order correlations. Survivors' turnover intentions were not uniform across time. Turnover intentions were generally high at $\mathrm{T} 2(\mathrm{M}=3.48, \mathrm{SD}=1.07)$, and notably lower at $\mathrm{T} 3(\mathrm{M}=1.85, \mathrm{SD}=.98)$. What is of more interest, however, was the relationship revealed in Figure 2 that showed a moderate positive longitudinal relationship among T2 and T3 turnover intentions. The implication of this finding is that survivors' turnover intentions at T2 do not influence subsequent turnover intentions alone; the combination of the direct and indirect effects in the longitudinal path model led to a result that is different from the crosssectional zero order correlations.

Influences from the composition variables. Last, the composition variables revealed few notable relationships when considered along with the variables in the model. Age was modestly related to changes in betweenness centrality in the model (path coefficient $=.18, p<.10$ ) showing that older workers experienced greater increases in centrality across T1 and T2; this most likely occurred because their younger colleagues viewed them as being trustworthy and likely sought out information and support from them in the immediate postdownsizing network (Brockner et al., 1997). At T2, hierarchical level was significantly related to the participants' changes in centrality (path coefficient $=.22, p<.05$ ), indicating that the management personnel showed the greatest increases in centrality in the first postdownsizing period. Practically speaking, it would make sense in a postdownsizing environment that managers would show an increase in the number of relationships they mediate, particularly when surviving workers find themselves in need of work-related information and in possession of information that may be 
useful to other coworkers. Likewise at T3, hierarchical level was modestly related to changes in information adequacy (path coefficient $=.18, p<.10$ ), showing that management personnel were able to continue to build a higher level of perceived information adequacy in the postdownsizing environment after the network stabilized. Hierarchical level was negatively related to turnover intentions at T3 (path coefficient $=-.22, p<.10$ ) suggesting that the clerical and staff members were more likely to turnover at T3 than the management personnel. Although turnover intentions had returned to predownsizing levels by T3, this finding suggests that lower level personnel may have been apprehensive about keeping their jobs. This finding is not surprising particularly when the lower level employees view the postdownsizing environment as less appealing and with fewer opportunities for advancement (Podolny \& Baron, 1997). Last, in the model at T2 the engineering department showed a significant increase in perceived information adequacy at T2 (path coefficient $=.22, p<.05$ ), and the marketing department showed a negative relationship to turnover intentions (path coefficient $=-.19, p<.10$ ). This indicates that there were a few significant differences in how each department reacted in the immediate postdownsizing environment, with engineering showing a notable gain in perceptions information inadequacy and the marketing department reporting a lower level of turnover intentions.

\section{Study Limitations}

Measurement intervals are an important consideration in change-based research (Zaheer, Albert, \& Zaheer, 1999). The sampling frame selected in the current investigation assessed communication relationships and work-related reactions 2 months prior to and 2 and 4 months following a downsizing event. Although the levels of the survivors' perceived information adequacy and turnover intentions returned to predownsizing levels within a 4-month period 
following the downsizing, if the sampling frame involved collection in 30-day intervals or a 6month sampling frame as applied by Shah (2000), the conclusions reached through these data may have been starkly different. At T2, the survivors' reactions for the most part were still quite negative and did not stabilize until T3. It remains unclear at what point prior to T3 the survivors' reactions became more positive, and more important what factors influenced that shift. In fact, survivors may have held their most negative feelings about the downsizing in the first month following the announcement. Consequently, until more data are collected prior to and following downsizing events the degree of reaction shifts among downsizing survivors will not be fully known. Therefore, the rationale for selecting a sampling frame should be carefully specified in longitudinal research attempting to gauge change (Zaheer et al., 1999). In addition, as Podolny and Baron (1997) and Shah (2000) have demonstrated, the selection of network content (e.g., instrumental vs. expressive content) plays a critical role in research findings. As more longitudinal studies are conducted, clearer ground will be established to guide the selection of network content and sampling intervals.

In this field-based network study, a relatively small sample was used. Although it may be methodologically desirable to garner a large sample to investigate the issues presented in the current study, the sample of the current study was inherently limited by the organization itself. In this case, the network sample represented 8 of the 11 departments in the corporate office, which captured $80 \%$ of the total network at three points in time. Studies of organizational networks are necessarily limited by the size of the organization. It is, therefore, unwise to suggest that by default only "large" field samples be used. For the discovery and advancement of organizationalbased knowledge, field studies are a necessary element, statistical and methodological concerns notwithstanding. 


\section{Pragmatic Implications}

Although it appears that the effects for centrality and information sufficiency may be limited and contingent (cf., Hartman \& Johnson, 1989; Ibarra \& Andrews, 1993), downsizing survivors' network centrality can still be used to provide critical insight into individual-level reactions to an organizational event. In a network, social, human, and financial capital are exchanged among network members to varying degrees, and network relationships following organizational downsizing take time to develop and nurture to reestablish benefits relating to network access and position (cf., Burt, 1997, 2000). It is clear from the current investigation that changes in centrality immediately following the downsizing influence perceived information adequacy that then influence survivors' turnover intentions. However, changes to survivors' access and control of information in the immediate postdownsizing network seem to be more critical than in the later period, suggesting that network stabilization has a calming effect on the postdownsizing organization. In the immediate postdownsizing environment, it seems that at a minimum those involved with the organizational change would require enhanced work-related information to help them with the transition through the immediate more turbulent postdownsizing environment to a point of greater organizational and network stability several months ahead. Given the longitudinal nature of the current investigation, it is now possible to specifically relate an enhanced need for information to changes in network centrality. As noted

in Table 4, to some degree I also can suggest that the stabilization of a postdownsizing network (evidenced by smaller shifts in centrality) leads to higher perceptions of information adequacy and improved job-related attitudes in the postdownsizing environment. 
These findings raise additional points for discussion. As individuals' work environments change as result of downsizing, they will assess what has changed in their day-to-day work activities and will make needed adjustments to complete their work and gather the needed information and access to function properly in the postdownsizing environment. As contacts are removed or changed, it will take network members time to evaluate what they have gained and what they have lost. Over time, they will be able to determine the value of work-related information as it becomes available to them. For example, Hypothesis 3 and Hypothesis 4 showed that changes in betweenness centrality and perceptions of information adequacy are inversely related over time. As a valued gain in network position or an increase in information flow is realized, members attempt to maintain the connections that produced that gain. Conversely, when a loss is realized, members will attempt to fill that loss if it is viewed as necessary for proper work functioning. These findings are consistent with Susskind et al.'s (1998) findings that survivors who lost network contacts following an organizational downsizing (i.e., increased structural holes) reported higher levels of perceived chaos in the organization and were less open and willing to the change process resulting from the downsizing, whereas those survivors whose network tightened by having structural holes close in their network perceived less organizational chaos and were more open to the change resulting from the downsizing. Included in this set of findings is that through the network stabilization process members find their way. Not because they want to, but because they have to. Downsizing survivors will align themselves with people that can help them and avoid or distance themselves from people who cannot. Each person's value in the network will be determined by what they bring to the table. That being said, however, not all network members can completely control whom they work with and their sources of information. 
Researchers and managers alike may find it useful to examine network centrality when considering the influence of a workforce reduction on surviving employees as one of the many characteristics in organizational network. Network change will initially influence the configuration of network relationships and require some level of individual member adjustment; however, when network members become situated, perceptions of organizational activities and interaction will likely improve or at least stabilize to some extent (Podolny \& Baron, 1997), noting that regardless of the stabilization a certain number of network members will likely feel displaced. With network analysis an examination of changes to betweenness centrality can be used to explain how organizational change and development activities are likely to influence future employee interaction throughout the organizational network and can be used to provide support to change initiators in their efforts to provide postdownsizing assistance to their surviving employees.

Future research should also directly examine employees' uncertainty resulting from network reconfigurations. In addition to reactions related to receiving sufficient amounts of information, researchers should explore uncertainty related to enlarged job descriptions or trust in new task relationships (Mishra \& Spreitzer, 1998)—both common outcomes of downsizing. The effects of increases or decreases in centrality on employees may be compounded by new responsibilities and/or beginning to work with new coworkers or direct reports. Employees with distinctly new roles following a network reconfiguration may have great difficulty in identifying effective work relationships and resources as a result of changes to their network position. 


\section{References}

Abelson, M. A. (1987). Examination of avoidable and unavoidable turnover. Journal of Applied Psychology, 72, 382-386.

Amburgey, T. L., Kelly, D., \& Barnett,W. P. (1993). Resetting the clock: The dynamics of organizational change and failure. Administrative Science Quarterly, 38, 51-83.

Baldwin, T. T., Bedell, M. D., \& Johnson, J. L. (1997). The social fabric of a team-based MBA program: Network effects on student satisfaction and performance. Academy of Management Journal, 40, 1369-1397.

Borgatti, S. P., Everett, M. G., \& Freeman, L. C. (1999). UCINET 5 for Windows: Software for Social Network Analysis version 5.3.5. Natick, MA: Analytic Technologies.

Brass, D. J., \& Burkhardt, M. E. (1992). Centrality and power in organizations. In N. Nohria \& R. G. Eccles (Eds.), Networks and organizations: Structure, form and action (pp. 191215). Boston: Harvard Business School Press.

Brass, D. J., \& Burkhardt, M. E. (1993). Potential power and use: An investigation of structure and behavior. Academy of Management Journal, 36, 441-470.

Brockner, J. (1988). The effects of work layoffs on survivors: Research, theory and practice. Research in Organizational Behavior, 10, 213-255.

Brockner, J., Davy, J., Carter, C. (1985). Layoffs, self-esteem, and survivor guilt: Motivational, affective, and attitudinal consequences. Organizational Behavior and Human Decision Processes, 36(2), 229-244.

Brockner, J., Grover, S., Reed, T., DeWitt, R., \& O’Malley, M. (1987). Survivors' reactions to layoffs: We get by with a little help for our friends. Administrative Science Quarterly, 32(4), 526-541. 
Brockner, J., Weisenfeld, B. M., Reed, T., Grover, S., \& Martin, C. (1993). Interactive effect of job content and context on the reactions of layoff survivors. Journal of Personality and Social Psychology, 64, 187-197.

Brockner, J.,Wiesenfeld, B., Stephan, J., Hurley, R., Grover, S., Reed, T., et al. (1997). The effects on layoff survivors of their fellow survivors' reactions. Journal of Applied Social Psychology, 27, 835-863.

Burt, R. S. (1997). The contingent value of social capital. Administrative Science Quarterly, 42, 339-365.

Burt, R. S. (2000). Social capital versus structural holes. In N. Lin, K. Cook, \& R. Burt (Eds.) Social capital (pp. 31-56). Hawthorne, NY: Aldine De Gruyter.

Caplan, G., \& Teese, M. (1997). Survivors: How to keep your best people on board after downsizing. Palo Alto, CA: Davies-Black.

Casey, M., Miller, V. D., \& Johnson, J. R. (1997). Survivor's information seeking following a reduction in workforce. Communication Research, 24, 755-781.

Cross, R., \& Cummings, J. N. (2004). Tie and network correlates of individual performance in knowledge intensive work. Academy of Management Journal, 47, 938-951.

Cummings, J. N., \& Cross, R. (2003). Structural properties of work groups and their consequences for performance. Social Networks, 25, 197-210.

Davy, J. A., Kinicki, A. J., \& Scheck, C. L. (1991). Developing and testing a model of survivor responses to layoffs. Journal of Vocational Behavior, 38, 302-317.

Feeley, T. H. (2000). Testing a communication network model of employee turnover based on centrality. Journal of Applied Communication Research, 23, 370-387. 
Feeley, T. H., \& Barnett, G. A. (1997). Predicting employee turnover from communication networks. Human Communication Research, 23, 370-387.

Freeman, L. C. (1979). Centrality in social networks: Conceptual clarification. Social Networks, 2, 215-239.

Gutknecht, J. E., \& Keys, J. B. (1993). Mergers, acquisitions and takeovers: Maintaining morale of survivors and protecting employees. Academy of Management Executive, 7, 26-36.

Hackman, J. R., \& Oldham, G. R. (1975). Development of the job diagnostic survey. Journal of Applied Psychology, 60, 159-170.

Hartman, R. L., \& Johnson, J. D. (1989). Social contagion and multiplexity: Communication networks as predictors of commitment and role ambiguity. Human Communication Research, 15, 523-548.

Hartman, R. L., \& Johnson, J. D. (1990). Formal and informal group communication structures: An examination of their relationship to role ambiguity. Social Networks, 12, 127-151.

Hayduk, L. A. (1987). Structural equation modeling with LISREL: Essentials and advances. Baltimore: Johns Hopkins University Press.

Hayduk, L. A. (1996). LISREL: Issues strategies and debates. Baltimore: Johns Hopkins University Press.

Hollingshead, A. B. (2001). Cognitive interdependence and convergent expectations in transactive memory. Journal of Personality and Social Psychology, 81, 1080-1089.

Hunter, J. E., \& Hamilton, M. A. (1995). Pathe: A program in basica. Unpublished manuscript, University of Connecticut, Storrs.

Ibarra, H. (1992). Homophily and differential returns: Sex differences in network structure and access in an advertising firm. Administrative Science Quarterly, 37, 422-447. 
Ibarra, H. (1993). Network centrality, power, and innovation involvement: Determinants of technical and administrative roles. Academy of Management Journal, 36, 471-501.

Ibarra, H. (1995). Race, opportunity, and diversity of social circles in managerial networks. Academy of Management Journal, 38, 673-703.

Ibarra, H., \& Andrews, S. B. (1993). Power, social influence, and sense making: Effects of network centrality and proximity on employee perceptions. Administrative Science Quarterly, 38, 277303.

Johnson, J. R., Bernhagen, M. J., Miller, V. D., \& Allen, M. (1996). The role of communication in managing reductions in work force. Journal of Applied Communication Research, 24, 165-180.

Jöreskog, K. G., \& Sörbom, D. (1993). LISREL for Windows 8.12a. Chicago: Scientific Software International.

Kozlowski, S. W. J., Chao, G. T., Smith, E., \& Hedlund, J. (1993). Organizational downsizing: Strategies, interventions, and research implications. In C. L. Cooper \& I. T. Robertson (Eds.), International review of industrial and organizational psychology (pp. 264-322). New York: John Wiley.

Krackhardt, D. (1992). The strength of strong ties: The importance of philos in organizations. In N. Nohria \& R. G. Eccles (Eds.), Networks and organizations (pp. 216-239). Boston: Harvard Business School Press.

Krackhardt, D., \& Porter, L. W. (1985). When friends leave: A structural analysis of the relationship between turnover and stayers' attitudes. Administrative Science Quarterly, 30, 242-261. 
Krackhardt, D., \& Porter, L. W. (1986). The snowball effect: Turnover embedded in communication networks. Journal of Applied Psychology, 71, 50-55.

Kraut, A. I. (1975). Predicting turnover of employees from measured job attitudes. Organizational Behavior and Human Performance, 13, 233-243.

Laumann, E. O., Marsden, P. V., \& Prensky, D. (1983). The boundary specification problem in network analysis. In R. S. Burt \& M. J. Minor (Eds.), Applied network analysis: A methodological introduction (pp. 18-34). Beverly Hills, CA: Sage.

Lawler, E. E. (1986). High-involvement management. San Francisco: Jossey-Bass.

Loehlin, J. C. (1998). Latent variable modeling: An introduction to factor, path, and structural analysis (3rd ed.). Mahwah, NJ: Lawrence Erlbaum.

Meyer, J. P., Allen, N. J., \& Smith, C. A. (1993). Commitment to organizations: Extension and test of a three-component conceptualization. Journal of Applied Psychology, 78, 538-551.

Miller, V. D., Johnson, J. R., \& Grau, J. (1994). Antecedents of willingness to participate in a planned organizational change. Journal of Applied Communication Research, 22, 59-80.

Mishra, A. K., \& Spreitzer, G. M. (1998). Explaining how survivors respond to downsizing: The roles of trust, empowerment, justice, and work redesign. Academy of Management Review, 23, 567-588.

Monge, P. R., \& Contractor, N. S. (1987). Communication networks: Measurement techniques In C. H. Tardy (Ed.), A handbook for the study of human communication (pp. 107-138). Norwood, NJ: Ablex.

Morrison, E. W. (2002). Information seeking within organizations. Human Communication Research, 28, 229-242. 
Morrison, E. W., \& Vancouver, J. B. (2000). With-in person analysis of information seeking: The effects of perceived costs and benefits. Journal of Management, 26, 119-137.

Mullen, B., Johnson, C., \& Salas, E. (1991). Effects of communication structure: Components of positional centrality. Social Networks, 3, 169-186.

O’Neill, H. M., \& Lenn, D. J. (1995). Voices of survivors: Words that downsizing CEOs should hear. Academy of Management Executive, 9, 23-33.

Podolny, J. M., \& Baron, J. N. (1997). Resources and relationships: Social networks and mobility in the workplace. American Sociological Review, 62, 673-693.

Rice, R. E. (1993). Using network concepts to clarify sources and mechanisms of social influence. In W. D. Richards \& G. A. Barnett (Eds.), Progress in communication sciences (Vol. 12, pp. 43-67). Norwood, NJ: Ablex.

Rodwell, J. J., Kienzle, R., \& Shadur, M. A. (1998). The relationships among work related perceptions, employee attitudes, and employee performance: The integral role of communication. Human Resource Management, 37(3/4), 277-293.

Salancik, G. R., \& Pfeffer, J. (1978). A social information processing approach to job attitudes and task design. Administrative Science Quarterly, 23, 224-253.

Shah, P. P. (1998). Who are employees' social referents? Using a network perspective to determine referent others. Academy of Management Journal, 41, 249-268.

Shah, P. P. (2000). Network deconstruction: The structural implications of downsizing. Academy of Management Journal, 43, 101-112.

Stefanone, M. A. (2004). Locus of control, instrumental action, and the pursuit of social capital. Unpublished doctoral dissertation, Cornell University, Ithaca, NY. 
Stokman, F., van Duijn, M., \& Snijders, T. (2006). StOCNET 1.7: An open system for the advanced statistical analysis of social networks (SIENA module version 2.4b). Groningen, The Netherlands: Science Plus Group bv.

Susskind, A. M., Miller, V. D., \& Johnson, J. D. (1998). Downsizing and structural holes: Their impact on layoff survivor's perceptions, organizational chaos, and openness to change. Communication Research, 25, 30-65.

Synder, R. A., \& Morris, J. H. (1984). Organizational communication and performance. Journal of Applied Psychology, 69, 461-465.

Tett, R. P., \& Meyer, J. P. (1993). Job satisfaction, organizational commitment, turnover intention, and turnover: Path analyses based on meta-analytic findings. Personnel Psychology, 46, 259-291.

Wegner, D. M. (1987). Transactive memory: A contemporary analysis of the group mind. In B. Mullen \& G. R. Goethals (Eds.), Theories of group behavior (pp. 185-208). New York: Springer-Verlag.

Zaheer, S., Albert, S., \& Zaheer, A. (1999). Time scales and organizational theory. Academy of Management Review, 24, 725-741. 
Table 1. Regression Analyses of the Control Variables on $\Delta$ Centrality, $\Delta$ Information Sufficiency, and Turnover Intentions at Time 2

(T2) and Time $3(\mathrm{~T} 3)$

\begin{tabular}{|c|c|c|c|c|c|c|}
\hline & $\begin{array}{c}\Delta \text { Centrality } \\
\text { at T2 }\end{array}$ & $\begin{array}{c}\Delta \text { Centrality } \\
\text { at } \mathrm{T} 3\end{array}$ & $\begin{array}{c}\Delta \text { Information } \\
\text { Sufficiency at } \mathrm{T} 2\end{array}$ & $\begin{array}{c}\Delta \text { Information } \\
\text { Sufficiency at } \mathrm{T} 3\end{array}$ & $\begin{array}{c}\text { Turnover } \\
\text { Intentions at } \mathrm{T} 2\end{array}$ & $\begin{array}{c}\text { Turnover } \\
\text { Intentions at } \mathrm{T} 3\end{array}$ \\
\hline Variables & $\beta$ & $\beta$ & $\beta$ & $\beta$ & $\beta$ & $\beta$ \\
\hline Sex & -.22 & -.05 & -.04 & -.13 & .06 & .24 \\
\hline Education & -.17 & -.05 & -.02 & -.03 & -.03 & -.001 \\
\hline Hierarchical level & $-.32^{* *}$ & .17 & .05 & $.28^{*}$ & -.04 & $-.44^{* * * *}$ \\
\hline Tenure & -.18 & .09 & .04 & .08 & .09 & -.21 \\
\hline Unit change & -.09 & .02 & -.18 & -.08 & -.05 & .08 \\
\hline Department (Engineering) & .18 & -.06 & $.31 *$ & .08 & $-.30^{*}$ & $-.25^{*}$ \\
\hline Department (Marketing) & -.01 & -.03 & .04 & -.09 & $-.26^{*}$ & .08 \\
\hline Age & $.44^{* * *}$ & -.01 & -.10 & .10 & .01 & .16 \\
\hline Equation $F(d f 1, d f 2)$ & $1.85(11,82)^{*}$ & $.24(11,82)$ & $1.01(11,80)$ & $.73(11,81)$ & $.85(11,81)$ & $1.97(11,82)^{*}$ \\
\hline Adjusted $R^{2}$ & .09 & .03 & .001 & -.03 & -.01 & .10 \\
\hline
\end{tabular}

Note: $\mathrm{df} 1$ = model; $\mathrm{df} 2=$ error. The regression coefficients are standardized, and t tests determined the significance of each coefficient. The engineering and marketing departments were the only departments that showed significant effects in the model, therefore the effects of the other five units were not included.

$* p<.05 . * * p<.01 . * * * p<.001$. 
Table 2. Descriptive Statistics and Correlations of the Latent Variables.

\begin{tabular}{|c|c|c|c|c|c|c|c|c|c|c|c|c|}
\hline & $M$ & $S D$ & (1) & (2) & (3) & (4) & (5) & (6) & (7) & (8) & $(9)$ & $(10)$ \\
\hline (1) $\Delta$ Centrality at $\mathrm{T} 2$ & .64 & 1.51 & $(-)$ & & & & & & & & & \\
\hline (2) $\Delta$ Centrality at $\mathrm{T} 3$ & -.15 & .73 & $-.32^{* * *}$ & $(-)$ & & & & & & & & \\
\hline (3) $\Delta$ Information adequacy at $\mathrm{T} 2$ & -1.38 & 1.34 & $.28^{* *}$ & -.14 & $(.84)$ & & & & & & & \\
\hline (4) $\Delta$ Information adequacy at T3 & 1.57 & 1.40 & $-.27^{* *}$ & $.20^{*}$ & $-.61^{* * * *}$ & $(.89)$ & & & & & & \\
\hline (5) Turnover intentions T2 & 3.48 & 1.07 & $-.36^{* * * *}$ & .10 & $-.67 * * *$ & $.58 * * *$ & $(.85)$ & & & & & \\
\hline (6) Turnover intentions T3 & 1.85 & .98 & -.03 & -.15 & -.02 & $-.40^{* * * *}$ & -.05 & $(.77)$ & & & & \\
\hline (7) Hierarchical level & - & - & .22 & .11 & -.01 & .19 & -.05 & $-.33 * * *$ & $(-)$ & & & \\
\hline (8) Age & 32.90 & 9.05 & .19 & -.03 & -.10 & .19 & .01 & -.03 & .01 & $(-)$ & & \\
\hline (9) Department (Engineering) & - & - & .08 & -.03 & $.22 *$ & .02 & -.17 & -.12 & -.08 & .19 & $(-)$ & \\
\hline (10) Department (Marketing) & - & - & .07 & -.02 & .01 & -.11 & -.18 & -.08 & .15 & -.10 & -.17 & $(-)$ \\
\hline
\end{tabular}

Note: Listwise $\mathrm{N}=91$; reliability coefficients (Cronbach's $\alpha$ ) appear in the parentheses along the diagonal and were not calculated for the network measures or the control variables.

$* p<.05 . * * p<.01 . * * * p<.001$. 
Table 3. Descriptive Statistics and Correlations for the Primary Variables Not Converted to Change Scores.

\begin{tabular}{|c|c|c|c|c|c|c|c|c|c|c|c|}
\hline Variable & $M$ & $S D$ & (1) & (2) & (3) & (4) & (5) & (6) & (7) & (8) & (9) \\
\hline T1 Centrality & 2.43 & 4.69 & - & & & & & & & & \\
\hline T2 Centrality & 1.81 & 3.10 & $.78^{* * * * *}$ & - & & & & & & & \\
\hline T3 Centrality & 1.65 & 2.85 & $.75^{* * * *}$ & $.97^{* * * * * *}$ & - & & & & & & \\
\hline T1 Information adequacy & 3.95 & .76 & -.19 & -.12 & -.09 & $(.83)$ & & & & & \\
\hline $\mathrm{T} 2$ Information adequacy & 2.55 & 1.13 & -.02 & .15 & .15 & .04 & (.86) & & & & \\
\hline T3 Information adequacy & 4.13 & .96 & $-.35^{* * * *}$ & $-.33^{* *}$ & $-.30^{* *}$ & .02 & .11 & $(.96)$ & & & \\
\hline T1 Turnover intentions & 2.04 & .82 & .15 & .05 & .02 & $-.78 * * *$ & -.11 & .06 & $(.78)$ & & \\
\hline $\mathrm{T} 2$ Turnover intentions & 3.51 & 1.04 & .01 & -.19 & -.18 & -.03 & $-.81^{* * * *}$ & -.10 & .12 & $(.85)$ & \\
\hline T3 Turnover intentions & 1.83 & .97 & $.36^{\text {***** }}$ & $.28 * *$ & $.27^{* *}$ & .08 & .00 & $-.58^{\text {***** }}$ & -.18 & -.01 & $(.77)$ \\
\hline
\end{tabular}

Note: Listwise $N=91$; reliability coefficients (Cronbach's $\alpha$ ) are reported along the diagonal in parentheses and were not calculated for the centrality indices.

$* p<.05 . * * p<.01 . * * * p<.001$. 
Table 4. Network Descriptive Statistics for Each Time Period.

\begin{tabular}{lccc}
\hline & $\mathrm{T} 1$ & $\mathrm{~T} 2$ & $\mathrm{~T} 3$ \\
\hline Number of ties & 652 & 679 & 705 \\
Average degree & 6.72 & 7.00 & 7.26 \\
Density & .070 & .073 & .076 \\
Dyad counts (mutual) & 287 & 263 & 261 \\
Dyad counts (asymmetric) & 78 & 153 & 183 \\
\hline
\end{tabular}




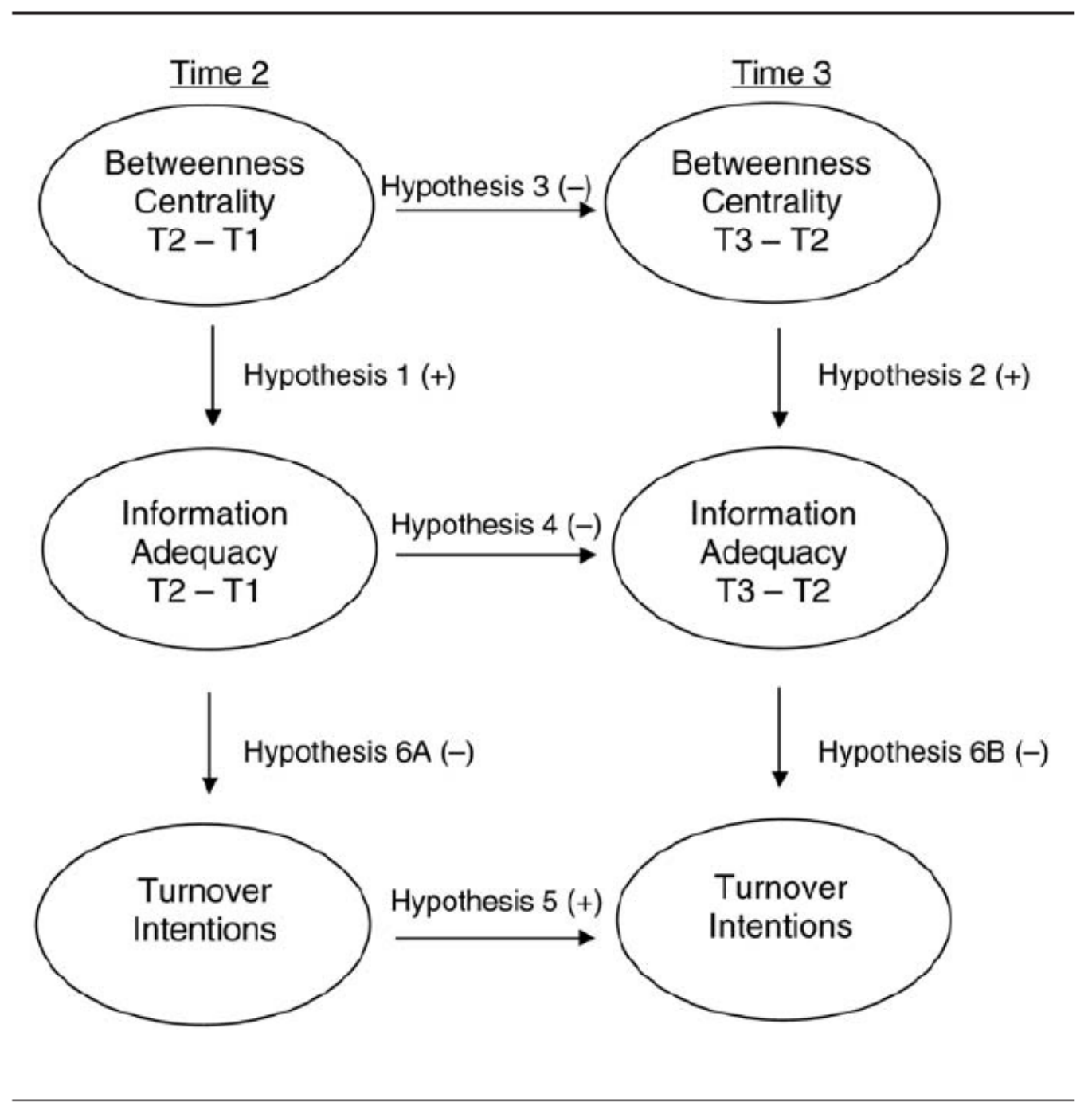

Figure 1. Proposed Longitudinal Model of Network Centrality, Perceived Information Adequacy, and Turnover Intentions. 


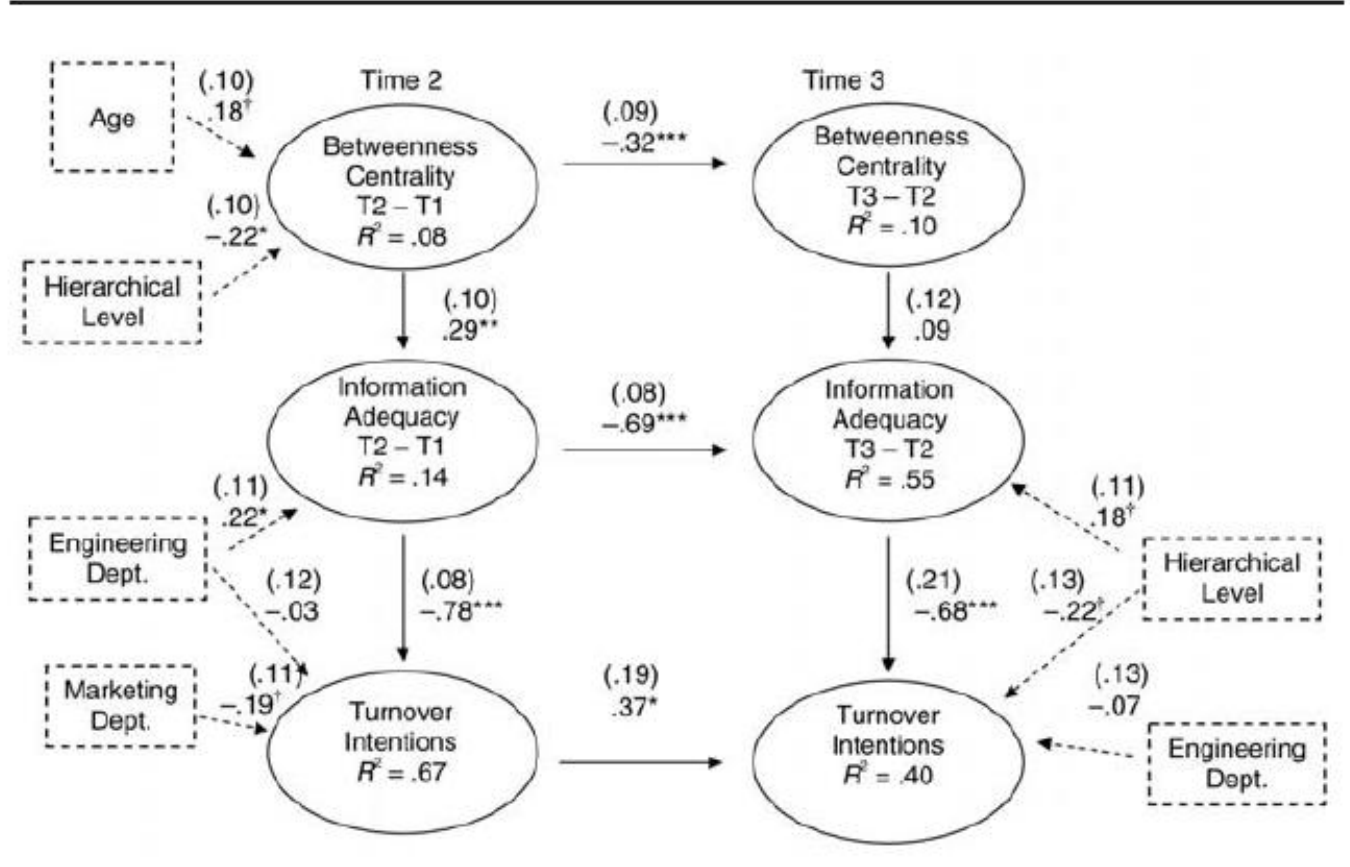

Figure 2. Longitudinal Model of Network Centrality, Perceived Information Adequacy, and Turnover Intentions 